\title{
Arbitraje Comercial Internacional: Intervención Jurisdiccional en el Arbitraje
}

Daniel Robalino 1

\section{Sumario}

1. Introducción. 2. El arbitraje comercial internacional en la Constitución ecuatoriana. 3. Intervención judicial y revisión de laudos. 3.1 Judicialización del arbitraje. 3.2 Constitucionalización del arbitraje. 4. Consideraciones finales.

\section{INTRODUCCIÓN}

El 20 de octubre de 2008 entró en vigencia la nueva Constitución Política del Ecuador, aprobada mayoritariamente por el pueblo ecuatoriano en referéndum $y_{\text {t }}$ redactada por la Asamblea Nacional Constituyente.

La nueva Constitución del Ecuador, en cuanto a sus principios rectores, se aparta de la teoría clásica constitucional y se fundamenta en la corriente teórica denominada neoconstitucionalismo. Consecuentemente, se aparta del principio de pesos y contrapesos para adoptar los principios de ponderación y proporcionalidad de derechos.

El texto de la nueva constitución reconoce el arbitraje, pero limita la posibilidad de acudir a instancias internacionales y entrevé la posibilidad de revisar el fondo de laudos firmes

1. Abogado por la Universidad San Francisco de Quito. Asociado en Paz Horowitz Robalino Garcés. 
mediante mecanismos constitucionales como la Acción Extraordinaria de Protección.

Por lo anterior, quienes utilizan el arbitraje como método de solución de controversias temen que la judicialización desnaturalice el proceso.

Este ensayo tiene por objeto determinar el rol de las Cortes respecto del arbitraje y los efectos de la judicialización, para lo cual tratará: (i) el régimen constitucional ecuatoriano que regula el arbitraje comercial internacional, (ii) las restricciones constitucionales al arbitraje internacional, (iii) las acciones constitucionales y legales que permiten la revisión de los laudos arbitrales y (iv) un breve análisis comparado sobre la judicialización del arbitraje en Iberoamérica.

\section{El Arbitraje Comercial Internacional en la CONSTITUCión ECUATORIANa}

La Constitución ecuatoriana expedida en el año 2008 reconoce de manera expresa a la institución arbitral, como uno de los métodos alternativos de solución de controversias. En este sentido, el artículo 190 de la Constitución señala:

Art. 190.- Se reconoce el arbitraje, la mediación y otros procedimientos alternativos parn la solución de conflictos. Estos procedimientos se aplicarán con sujeción a la ley, en materias en las que por su naturaleza se pueda transigir.

En la contratación pública procederá el arbitraje en derecho, previo pronunciamiento favorable de la Procuradurín General del Estndo, conforme a las condiciones establecidas en la ley.

Vale mencionar que el pronunciamiento favorable del Procurador General del Estado, en materia de contratación pública, es ahora un requisito previo. La Constitución anterior 
(1998) y la Ley de Arbitraje y Mediación (1997) disponían que el dictamen del procurador debía pedirse "Si la cláusula arbitral se celebrara una vez surgida la controversia" 2 .

Considerando que Ecuador, en la última década, fue demandado repetidas veces en instancias arbitrales internacionales, la Asamblea Nacional Constituyente que promulgó la Constitución vigente se vio en la necesidad de limitar la posibilidad de que el Estado se someta a instancias internacionales. Lo anterior dio como resultado el artículo 422:

Art. 422.- No se podrá celebrar tratados o instrumentos internacionales en los que el Estado ecuatoriano ceda jurisdicción soberana a instancins de arbitraje internacional, en controversias contractuales o de indole comercial, entre el Estado y personas naturales o juridicas privadas.

Se exceptuan los tratados e instrumentos internacionales que establezcan la solución de controversias entre Estados y ciudadanos en Latinoamérica por instancins arbitrales regionales o por órganos jurisdiccionales de designación de los países signatarios. No podrán intervenir jueces de los Estados que como tales o sus nacionales sean parte de la controversia.

En el caso de controversins relacionadas con la deuda externa, el Estado ecuatorinno promoverá soluciones arbitrales en función del origen de la deuda y con sujeción a los principios de transparencia, equidad y justicia internacional.

De la norma citada, es posible concluir que:

2. Ley de Arbitraje y Mediación de Ecuador. Artículo. 4.- Podrán someterse al arbitraje regulado en esta Ley las personas naturales o juridicas que tengan capacidad para transigir, cumpliendo con los requisitos que establece la misma. Para que las diferentes entidades que conforman el sector público puedan someterse al arbitraje, además de cumplir con los requisitos que establece esta Ley, tendrán que cumplir los siguientes requisitos adicionales: a) Pactar un convenio arbitral, con anterioridad al surgimiento de la controversia; en caso de que se quisiera firmar el convenio una vez surgida la controversia, deberá consultarse al Procurador General del Estado, dictamen que será de obligatorio cumplimiento (...) 
(i) Existe una prohibición expresa para que el Estado celebre instrumentos internacionales en los cuales ceda "jurisdicción soberana a instancias de arbitraje internacional". Se debe considerar que tal prohibición aplica únicamente a instrumentos futuros, más no a aquellos que vigentes a la época de la promulgación de la Constitución. Caso contrario, implicaría una transgresión a las normas de Derecho Internacional Público y al principio de pacta sunt servanda contenido en la Convención de Viena.

(ii) La prohibición del Artículo 422 limita a las controversias "contractuales o de índole comercial" que involucren al Estado, más no a las relativas a inversión extranjera, consecuentemente, el Ecuador puede celebrar tratados de protección recíproca de inversiones (TBI).

Sobre esta norma, en palabras de PÉREZ y MARCHÁN "es innegable que la voluntad de los asambleistas era el blindar al Estado ecuatoriano de la obligación de someterse a cualquier tipo de arbitraje internacional, especialmente de inversión" ${ }^{3}$, sin embargo, los diversos procesos arbitrales iniciados en contra del Estado ecuatoriano en los últimos dos años, al amparo de Tratados Bilaterales de Inversión, evidencian que el artículo 422 no logró cumplir su cometido principal.

Establecido lo anterior, es importante considerar que la Constitución de 2008 tiene dos particularidades en cuanto a los tratados internacionales. El artículo $417^{4}$ estipula qué: "Los tratrdos internacionales ratificados por el Ecuador se sujetarán a lo establecido en ln Constitución".

3. Pérez Ordónez, Diego y Juan Manuel Marchín, "El Arbitraje Comercial Internacional En Ecuador". En la Obra Colectiva: El Arbitruje en Lntinomerica, compilada por Jorge Luis Collantes PAlestra. Lima: Palestra.

4. Constitución del Ecuador. Artículo 417.- Los tratados internacionales ratificados por el Ecuador se sujetarán a lo establecido en la Constitución. En el caso de los tratados y otros instrumentos internacionales de derechos humanos se aplicarán los principios pro ser humano, de no restricción de derechos, de aplicabilidad directa y de cláusula abierta establecidos en la Constitución. 
En la misma línea, el artículo $425^{5}$ de la Carta Política otorga a los tratados y convenios internacionales un estatus infraconstitucional, en consecuencia, el Estado al tratar de evitar procesos arbitrales internacionales o la ejecución de Laudos derivados de tales procesos, podrá alegar cuestiones localistas incluso a riesgo de contravenir el ya referido principio del pacta sunt servanda contenido en los artículos 26 y 27 de la Convención de Viena ${ }^{6}$.

Descritas las normas constitucionales que tutelan el arbitraje, es fundamental considerar que la LAM, regula el proceso arbitral en su totalidad y reconoce los procedimientos arbitrales internacionales ${ }^{7}$. La LAM, al tratar la ejecución de laudos internacionales, señala que aquellos se ejecutarán de la misma manera que los laudos nacionales ${ }^{8}$. Es decir, por la vía de apremio.

5. Constitución del Ecuador. Artículo 425. El orden jerárquico de aplicación de las normas será el siguiente: La Constitución; los tratados y convenios internacionales; las leyes orgánicas; las leyes ordinarias; las normas regionales y las ordenanzas distritales; los decrelos y reglamentos; las ordenanzas; los acuerdos y las resoluciones; y los demís actos y decisiones de los poderes públicos.

6. Convención de Viena (UN Doc A/Conf.39/27 (1969):

Artículo 26.- "Pacta sunt servanda". Todo tratado en vigor obliga a las partes y debe ser cumplido por ellas de buena fe.

Artículo 27. El derecho interno y la observancia de los tratados. Una parte no podrá invocar las disposiciones de su derecho interno como justificación del incumplimiento de un tratado. Esta norma se entenderá sin perjuicio de lo dispuesto en el artículo 46.

7. Ley de Arbitraje y Mediación Ecuador. Artículo 41.- Sin perjuicio de lo dispuesto en los tratados internacionales un arbitraje podrá ser internacional cuando las partes asf lo hubieren pactado, siempre y cuando se cumplan cualquiera de las siguientes requisitos:

a) Que las partes al momento de la celebración del convenio arbitral, tengan sus domicilios en estados diferentes;

b) Cuando el lugar de cumplimiento de una parte sustancial de las obligaciones o el lugar en el cual el objeto del hitigio tenga una relación más estrecha, esté situado fuera del estado en que, por lo menos una de las partes, tiene su domicilio; $o$,

c) Cuando el objeto del litigio se refiera a una operación de comercio internacional que sea susceptible de transacción y que no afecte o lesione los intereses nacionales o de la colectividad.

8. Ley de Arbitraje y Mediación Ecuador.

Artículo 42.- El arbitraje internacional quedará regulado por los tratados, convenciones, protocolos y demás actos de derecho internacional suscrilos y ratificados por el Ecuador. Toda persona natural o jurídica, pública o privada, sin restricción alguna es libre de estipular directamente o mediante referencia a un reglamento de arbitraje todo lo concerniente al procedimiento arbitral, incluyendo la constitución, la tramitación, el idioma, la legislación aplicable, la jurisdicción y la sede del tribunal, la cual podrá estar en el Ecuador o en país extranjero.

Para que el Estado o las instituciones del sector público puedan someterse al arbitraje internacional se estará a lo dispuesto en la Constitución y leyes de la República. 
Esto ha generado amplio debate acerca de si es o no necesario el proceso de reconocimiento o exequátur, previo la ejecución, o si los laudos internacionales pueden ejecutarse directamente.

La ejecución de laudos internacionales se complementa con los instrumentos internacionales de los cuales el Ecuador es parte y que son relevantes para este estudio, tales como la Convención sobre el Reconocimiento y Ejecución de Sentencias Arbitrales Extranjeras de 1958 (Convención de Nueva York), la Convención Interamericana sobre Arbitraje Comercial Internacional de 1975 (Convención de Panamá) y la Convención sobre Arreglo de Diferencias Relativas a Inversiones de 1966 (Convenio de Washington) ${ }^{9}$.

\section{INTERVENCión Judicial y Revisión de LAUdos}

\subsection{Judicialización del Arbitraje}

Gran parte de los países iberoamericanos adoptó en sus leyes de arbitraje el principio de intervención limitada de las Cortes Estatales, acorde al artículo 5 de la Ley Modelo de UNCITRAL ${ }^{10}$. Este principio tiene por objeto excluir cualquier poder que pudiere atribuirse a los Tribunales de justicia en virtud de otras leyes domésticas, aumentando así la independencia del arbitraje y la certeza de quienes lo utilizan.

Para que las diferentes entidades que conforman el sector público puedan someterse al arbitraje inlernacional se requerirá la autorización expresa de la máxima autoridad de la institución respectiva, previo el informe favorable del l'rocurador General del Estado, saivo que el arbitraje estuviere previsto en instrumentos internacionales vigentes.

Los laudos dictados dentro de un procedimiento de arbitraje internacional, tendrán los mis* mos efectos y serán ejecutados de la misma forma que los laudos dictados en un procedimiento de arbitraje nacional.

9. El gobierno ecuatoriano Denunció la Convención sobre Arreglo de Diferencias Relativas a Inversiones, en Julio de 2009. Sin embargo, existe un "Survival Clause" o cláusula de sobrevivencia que ampara por diez años las inversiones realizadas antes de la denuncia.

10. Art. 5. Alcance de la intervencion del tribunal. En los asuntos que se rijan por la presente Ley, no intervendrá ningún tribunal salvo en los casos en que esta Ley así lo disponga. 
En algunas jurisdicciones como la brasilera no está expresamente delimitado el rol de las Cortes Estatales y el alcance del principio Kompetence-Kompetence, lo que ha generado intromisiones jurisdiccionales en los procesos arbitrales. Sin embargo, en jurisdicciones como la Ecuatoriana, que reconoce en su lex arbitri el principio de intervención limitada, en aplicación normas de jerarquía constitucionales, las Cortes han permitido la intervención jurisdiccional en procesos arbitrales. Estudiaremos algunos casos.

En el caso ecuatoriano, el Laudo adquiere el carácter de cosa juzgada y de sentencia ejecutoriada (res iudicata) luego de transcurridos tres días de su notificación a las partes, sin perjuicio de la aclaración o ampliación que pueda hacer el tribunal a petición de parte.

El artículo 31 de la LAM señala "(...) Del laudo arbitral podrá interponerse ante el árbitro o tribunal arbitral, acción de nulidad para ante el respectivo presidente de la corte superior de justicin (...)".

Con esta acción de nulidad, las partes pueden solicitar a la Corte (órgano jurisdiccional) que revise la actuación in procedendo del árbitro, pues tiene por objeto asegurar, -como en un proceso judicial- el debido proceso, la legítima defensa y la tutela judicial efectiva que son principios de orden público y de jerarquía constitucional.

Consecuentemente, la Acción de Nulidad (junto con la ejecución forzosa de los laudos) son los únicos casos de auxilio judicial previstos en la LAM y procede taxativamente cuando:

Art. 31.- Cualquiera de las partes podrá intentar la acción de nulidad de un lnudo arbitral, cuando:

a) No se haya citado legalmente con la demanda y el juicio se ha seguido y terminado en rebeldín. Será preciso que In falta de citación haya impedido que el demandado deduzca sus excepciones o haga valer sus derechos $y$, además, que el demandado reclame por tal omisión al tiempo de intervenir en la controversia; 


$$
\begin{gathered}
\text { Arbitraje Comercial Internacional: } \\
\text { Intervención furisdiccional en el Arbitraje }
\end{gathered}
$$

b) No se haya notificado a una de las partes con las providencias del tribunal y este hecho impida o limite el derecho de defensa de la parte;

c) Cuando no se hubiere convocado, no se lumbiere notificado la convocatoria, o luego de convocada no se hubiere practicado las pruebas, a pesar de la existencin de hechos que deban justificarse;

d) El laudo se refiern a cuestiones no sometidas al arbitraje o conceda más allá de lo reclamado; $o$,

e) Cuando se hayan violado los procedimientos previstos por esta Ley o por las partes para designar árbitros o constituir el tribunal arbitral. (...)

En Brasil y Argentina se han dado casos de paralización de arbitrajes en curso (anti-arbitration injuctions) por orden judicial. Concretamente, en el caso Companhia Paranense de Energía -Copel-contra UEG Araucaria Ltda." un juez de primera instancia del Estado de Paraná ordenó la paralización de un arbitraje comercial internacional por considerar que "el arbitraje versaba sobre derechos no susceptibles de libre disposición (...) dado que involucraba intereses públicos al ser la parte demandada una entidad estatal".

En otros casos, los tribunales judiciales han admitido solicitudes de medidas cautelares judiciales orientadas a suspender los procedimientos arbitrales ya iniciados. Concretamente, la Cámara Nacional de Apelaciones en lo Civil y Comercial de la República Argentina suspendió el proceso arbitral iniciado por Usinas y Transporte Eléctrico del Uruguay v. Hidroeléctrica Piedra del Aguila S.A. y Nobel Coating S.A. ${ }^{12}$.

11. Copel v. UEG, Caso 24334/0000, 15 de marzo de 2004. Tomado de: Conejero Roos, Cristian y Renato Grion. "Arbitration in Brazil: The ICC Experience". En Arbitration in Brazil: Practice and Procedure. Juris Publishing, 2005.

12. Administración de Usinas y Transporte Eléctrico del Uruguay v. Hidroeléctrica Piedra del Águila. Cámara Nacional de Apelaciones en lo Civii y Comercial Federal, Sala 2, 26-08-2003. Tomado de la obra de MoccHi^, Valeria. "Arbitraje Comercial Internacional en Argentina: Marco Legal y Jurisprudencial". En: Arbitraje Comercial internacional en lbcroamirica. Wolters Klusver España, 2009. 
La intervención judicial en el arbitraje se ha dado por diversos motivos y utilizando acciones y recursos judiciales diferentes, sin embargo, el punto en común es que las cortes estatales han suspendidos los procesos arbitrales que derivan de un convenio arbitral válidamente celebrado. Esta injerencia no delimitada generó que en la región, sin mayor justificación, las cortes extiendan la interpretación de las causales de nulidad a niveles poco ortodoxos.

Por ejemplo, en Venezuela, la Ley de Arbitraje (cuyas causales de nulidad previstas en la Ley venezolana son similares a las contenidas taxativamente en el artículo 34(2) de la Ley Modelo de UNCITRAL) ${ }^{13}$ y la jurisprudencia han ratificado que la acción de nulidad es la única acción procedente contra un laudo, así lo señalo el Tribunal Supremo de Justicia de Venezuela en el caso Grupo Inmensa C.A. y otros v. Soficrédito Banco de Inversión C.A. ${ }^{14}$

Sin embargo, en el caso Venezolana de Televisión C.A. v. Elletronica Industriale S.P.A ${ }^{15}$, la corte interpretó las causales de nulidad tan ampliamente, que se permitió la anulación del laudo. La corte consideró que el laudo afectaba los intereses de una entidad estatal:

"La compañía anónima Venezolana de Televisión es un bien patrimonial que pertenece al Fisco Nacional y por ende al colectivo, en consecuencia hay un interés puiblico sobre todo por cuanto dicha empresa cumple un servicio público".

En Ecuador existe un precedente parecido, por el cual desde el año 2010, no se pueden ejecutar laudos en contra de la cuenta única del tesoro (por ser considerada un bien público).

13. Weininger, Bernardo y David Lindser. "Chapter Nine: Venezuela". En la Obra Colectiva: International Arbitration in Latin America, editada por Nigel BLACKaby. The Hague: Kluwer Law International, 2002, p. 251.

14. Grupo Inmensa C.A. y otros v. Soficrédito Banco de Inversión C.A. CF. Expediente 00-3203, sentencia de fecha 23 de mayo de 2001.

15. Venezolana de Televisión C.A. v. Elletronica Industriale SPA. Publicado en el Boletín del Comité Venezolano de Arbitraje número 17, 2006. pp. 4 - 10. 
Arbitrije Comercial Internacional:

Intervención Jurisdiccional en el Arbitraje

Por otro lado, cabe referirse a la intervención judicial en cuanto a la asimilación del árbitro con el juez, circunstancia que se ha repetido a lo largo de la región.

El Código Orgánico de la Función Judicial del Ecuador señala:

"Articulo 7.- La jurisdicción y la competencia nacen de la Constitución y la ley. Solo podrín ejercer la potestad jurisdiccional las juezas y jueces nombrados de conformidad con sus preceptos, (...). Los árbitros ejercerán funciones jurisdiccionales, de conformidad con la Constitución y la ley.

Artículo 17.- La administración de justicin por la Función Judicial es un servicio público, básico y fundamental del Estado, (...) El arbitraje, la mediación y otros medios alternativos de solución de conflictos establecidos por la ley, constituyen una forma de este servicio puiblico, (...)".

De manera similar, legislaciones como la Argentina aplican a los árbitros mecanismos y sanciones previstas para los jueces. En este sentido, la jurisprudencia argentina ha entendido que el árbitro es juez dentro del concepto constitucional del Tribunal, quedando sujeto a las reglas de disputa de competencia. Lo anterior se ha permitido incluso en procesos de arbitraje internacional.

La Cámara Nacional de Apelaciones en lo Comercial en el caso de Compañía General de Combustibles señaló:

"La solicitud de inhibitoria por la cual un juez estatal le solicita a un árbitro que se abstenga de conocer una disputa y, en caso que el árbitro se resista, se ha autorizado a que la contienda de competencia sea resuelta por un tribunal superior de la propia judicatura argentina"16.

16. Caso Compañía General de Combustibles. Failo de Corte Nacional de Apelaciones en lo Comercial, Sala B. Sepliembre de 1999. Jurisprudencia Argentina, vol. 2002-III, p. 53. Tomado de Grigera NAÓN, Horacio. "Arbitration in Latin America: Progress and Setbacks". En: Arbitration International. 2005. 
En Chile ocurre algo similar, pues se permite la interposición del denominado "recurso de queja" que constituye un recurso disciplinario que eventualmente podría anular un laudo arbitral si se demuestra que el árbitro cometió falta grave al dictar el fallo. La jurisprudencia chilena considera al árbitro como parte del poder judicial y consecuentemente permite que la Corte Suprema revise su actuación, como sucede también en Ecuador y Argentina. CONEjERo Roos, refiriéndose al recurso de queja, señala "aun cuando va dirigido a sancionar la conducta del árbitro puede afectar la validez del laudo arbitral" 17 .

A su vez, LINDSEY y RIESCO sostienen que "el recurso de queja eventualmente otorga a la Corte ... una libertad sustancial para dejar sin efecto un laudo arbitral internacional dictado en Chile basado en otras causales no especificadas y posiblemente más amplias" 18.

Por otro lado cabe decir que en Ecuador se han dado casos en los que miembros de tribunales arbitrales han sido objeto de acciones penales en su contra, generalmente por el delito de prevaricato. Aunque tales acciones estén dirigidas a los árbitros, y si bien en ciertos casos pueden ser legítimas; perjudican el normal desarrollo del proceso. Incluso, tales acciones podrían envolver al proceso en causales de nulidad aparentes antes de que exista algún dictamen condenatorio en contra de los árbitros imputados.

Sin perjuicio de lo expuesto, cabe recalcar que existe contradicción entre lo estudiado en los párrafos precedentes y la Ley de Arbitraje de Ecuador y de Chile que prevén la denominada Acción de Nulidad como el único recurso contra el laudo, lo que permite esperar que la indebida asimilación entre Juez y Árbitro por la jurisprudencia y la legislación secundaria lleve a riesgos inciertos a la hora de ejecutar laudos arbitrales, perjudicando la intención de las partes al excluir su controversia de la jurisdicción ordinaria.

17. Conejero Roos, Cristián. El Arbitrajc Comercial Internaciostal en lbcroamérica: Un Panoranta General. Madrid: La Ley, 2009, p. 91.

18. LindseY, David y Ricardo Riesco. "Selecting Clule as a place of Arbitration". En: International Business Litigation \& Arbitration. Vol, 1. 2006, p. 637. 


\subsection{Constitucionalización del Arbitraje}

El ex-Tribunal Constitucional del Ecuador, en el caso Iglesia de Jesucristo de los Santos de los Últimos Días v. Urbanizadora del Salado S.A. estableció que "los actos emanados de la jurisdicción convencional no atentan contra ningün derecho constitucional (...); y por lo tanto no son susceptibles de acción de anparo constitucional" 19 , en consecuencia sentó el precedente de que no era posible recurrir un laudo arbitral por medio de una acción constitucional de amparo. El referido fallo se dio en base a la constitución de 1998, que no preveía la Acción Extraordinaria de Protección.

El artículo 94 de la Constitución ecuatoriana vigente señala que:

Articulo 94.- Ln acción extraordinaria de protección procederá contra sentencias o autos definitivos en los que se haya violado por acción u omisión derechos reconocidos en la Constitución, y se interpondrá ante la Corte Constitucional. El recurso procederá cuando se hayan agotado los recursos ordinarios y extraordinarios dentro del término legal, a menos que la falta de interposición de estos recursos no fuera atribuible a la negligencia de la persona titular del derecho constitucional vulnerado.

La Corte Constitucional, considerando la norma antes citada en concordancia con los artículos 7 y 17 del Código Orgánico de la Función Judicial, admitió a trámite las acciones de protección seguidas contra laudos arbitrales en los casos de Transelectric S.A. v. laudo arbitral dictado por el tribunal arbitral de la Cámara de Comercio de Quito 20 e Hidrosan Cía. Ltda v. laudo arbitral dictado por el tribunal arbitral de la Cámara de la Construcción de Quito21.

19. Fallo dictado por la segunda sala del Tribunal Constitucional Ecuatoriano, con fecha 2 de diciembre de 1998, propuesto por la Iglesia de Jesucrislo de los Santos de los últimos días contra el laudo arbitral que siguió en contra de Urbanizadora del Salado S.A.

20. Corte Constitucional: Caso 0046 - 09 - EP, Acción Extraordinaria de Prolección presentada por el ingeniero Abdón Vicuña Izquierdo en su calidad de gerente general de la compañía Transelectric S.A. en contra del laudo arbitral dictado por el tribunal arbitral de la Cámara de Comercio de Quito dentro del proceso arbitral número 27 - 2007. 
De manera distinta, en el caso de Albán v. Castro (arbitraje independiente) en el que se interpuso una acción extraordinaria de protección contra el fallo de la Corte Superior que resolvió la acción de nulidad interpuesta contra el laudo, y en la cual el accionante solicitó a la Corte Constitucional que ordene al juez aquo aceptar la acción de nulidad que fue rechazada. La Corte Constitucional señaló:

"Los accionantes, si bien mencionan la vulneración de derechos constitucionales (debido proceso), la fundamentación con respecto a la misma está limitnda a un presunto incumplimiento de normas legales ... lo que no constituye argumentación constitucional válida. Por lo expuesto ... Inadinite a trámite la acción extraordinarin de protecciön"22.

Siguiendo con el análisis vale mencionar que en abril de 2011 un juez de Niñez y Adolescencia del Guayas, que conoció una acción ordinaria de protección relativa a un proceso arbitral $^{23}$, dejó sin efecto el laudo arbitral dictado por un tribunal arbitral de la Cámara de Comercio Ecuatoriana Americana. Este caso llama la atención, entre otros aspectos, por lo siguiente:

(i) Se trata de una acción ordinaria de protección, cuando en último caso debería tratarse de una acción Extraordinaria de Protección, por ser la vía por la cual se pueden revisar autos o sentencias definitivas,

(ii) Ordena a los particulares que dejen sin efecto el laudo, cuando no pueden hacerlo por carecer de facultades jurisdiccionales (debería ser el tribunal el llamado a dejar sin efecto el laudo),

21. Corte Constitucional del Ecuador: Acción Extraordinaria de protección $N^{\circ}$ 0204-09-EF presentado por Galo Vallejo Salas en su calidad de Gerente General de la Compañfa Hidrosan Cía. Ltda., en contra del laudo arbitral dictado por el doctor Hernán Quevedo.

22. Corte Constitucional: Caso 0421-10-EP, Albán v. Castro de 18 de octubre de 2010.

23. Caso El Progreso v. UMET. Fallo dictado por el Juez de Niñez y Adolescencia del Guayas, 28 de Abril de 2011. 
Arbitraje Comercial linternacional:

Intervencion jurisdiccioual en el Arbitrajc

(iii) Transgrede el principio de res iudicata que envuelve a los laudos arbitrales; $y$

(iv) La acción de protección fue propuesta por un tercero ajeno al proceso arbitral, quien no logró demostrar que el laudo generaba efectos erga omnes.

Dejando a un lado las acciones constitucionales de protección que se han propuesto en contra de laudos arbitrales, cabe hacer referencia a la acción de Medidas Cautelares Constitucionales y su pertinencia en el arbitraje.

El artículo 87 de la Constitución 2008, y el artículo 26 de la Ley de Garantías Jurisdiccionales y Control Constitucional señalan:

Constitución.- Artículo 87.- Se podrán ordenar medidas cautelares conjuntn o Independientemente de las acciones constitucionales de protección de derechos, con el objeto de evitar o hacer cesar la violación o amenaza de violación de un derecho.

LOGJCC.- Artículo 26.- Finalidad.- Las medidas cautelares tendrán por objeto evitar o cesar la amenaza o violación de los derechos reconocidos en ln Constituciön y en instrumentos internacionales sobre derechos humanos.

Las medidas cautelares deberán ser adecuadas a la violación que se pretende evitar o detener, tales como In commicación inmediata con la autoridad o persona que podría prevenir o detener la violación, la suspensión provisional del acto, la orden de vigilancin policial, la visita al lugar de los hechos. Ent ningún caso se podrán ordenar medidas privativas de la libertad.

En el proceso de medidas cautelares signado como 20102085, que conoció el Juez Octavo de Garantías Penales del Guayas, se concedió "la suspensión del proceso arbitral 075-2010 que comprende la audiencia de mediación convocada por el Director del Centro de Arbitraje y Mediación de la Cámara de Comercio de Quito

Revista Ecuatoriana de Arbitraje 
(...)", por considerar que no existía un convenio arbitral válidamente celebrado y que en consecuencia se exponía al accionante a un perjuicio irreparable.

Sin perjuicio de la validez constitucional de la resolución del Juez de Garantías Penales del Guayas, que no es materia de este estudio, las medidas cautelares interpuestas evitaron que el Tribunal arbitral pueda conocer y resolver sobre su propia competencia, transgrediendo así el principio Kompetenz-Kompetenz que rige el arbitraje.

Los precedentes constitucionales antes citados han evitado el normal desarrollo de los procesos arbitrales y la ejecución de laudos, sea en arbitrajes domésticos o internacionales. En países de la región hay precedentes similares.

En Colombia, por medio de una acción de tutela, la Corte Constitucional anuló un laudo arbitral sobre la base de que el laudo había violado el debido proceso, al fallar sobre un punto que, al parecer de la Corte, no era arbitrable. Este caso tiene particular relevancia porque la decisión constitucional fue contraria a la decisión a la del Consejo de Estado, que en Colombia es el juez natural y competente para conocer la anulación de los laudos $^{24}$. En este proceso, la Corte Constitucional señaló:

"Por consiguiente la Sala tutelará el debido proceso de la Gobernación del Valle del Cauca y anulará la sentencia del 11 de marzo de 2004 proferida por la sección Tercera de la Sala de lo Contencioso Administrativo del Consejo de Estado y el laudo arbitral del 24 de abril de 2003 que resolvió la controversia suscitada entre la Sociedad Concesiones de Infraestructura S.A. (CISA) y el Departamento del Valle del Cauca con ocasión del Contrato de Concesión GM-95-04-017. En consecuencia quedará en firme la liquidación unilateral del contrato de concesión que realizó la Gobernación del

24. Zuleta Londoño, Alberto. "La Protección Constitucional del Arbitraje". En la Obra Colectiva: El Arbitraje luternational: Tensiones Actuales, coordinada por Fernando MANTLLLA Sirrano. Bogota: Legis, 2007, p.77. 
Valle del Cauca mediante la Resolución 095 del 17 de septiembre de $2001^{\prime \prime 25}$

Para Zuleta Londoño, a pesar de que el fallo antes mencionado fue revocado en el año 2007, en Colombia sigue vigente la posibilidad de intentar acciones de tutela en contra de laudos arbitrales.

En Venezuela, el Tribunal Supremo de Justicia revisó laudos arbitrales extranjeros por medio de recursos constitucionales ordinarios (Amparo Constitucional). En el caso Corporación Todosabor C.A. v. Hageen-Daz International Shoppe Company Inc. ${ }^{26}$, la corte venezolana anuló el laudo dictado bajo las Reglas de la AAA (Asociación Americana de Arbitraje) en Miami con el fin de "preservar derechos fiudamentales garantizados por la Constitución de Venezuela, en la parte venezolana afectada".

Asimismo, en el caso Consorcio Barr CA v. Four Seasons27, la Corte Constitucional Venezolana determinó que el

"sometimiento de una acción arbitral en el extranjero no le cierra la puerta a ninguna de las partes a recurrir a las cortes venezolanas para dirimir cualquier asunto relacionado con el procedimiento arbitral, inclusive cuando ya el tribunal haya desestimado su validez o procedencia o cuando se encuentre deliberando sobre la acción" 28 .

Es decir, las cortes venezolanas podrían incluso evitar que los árbitros se declaren competentes desconociendo el principio Kompetenz-Kompetenz.

25. Corte Constitucional de Colombia, Sentencia T-481 del 11 de mayo de 2005. Ref: expediente T-980611 de Acción de Tutela. Se debe notar que dicha sentencia fue posteriormente revocada mediante sentencia SU-174 de 2007 por la Corte Constitucional.

26. Decisión de 14 de Febrero de 2006, Ita Monthly Report, Vol. 4, número 11, mayo 2006. Disponible en wwww.kluwerarbitration.com.

27. Consorcio Barr CA v. Four Seasons (exp. N 04-0163) publicado en www.tsj.govve

28. Di Ros^, Paolo y Rafael Cox Alosinr. "Control Judicial del Arbitraje: Siempre Tributario de un Foro Local". En la Obra Colectiva: El Arbitraje Internacional: Tensiones Actuales, coordinada por Fernando Mantilla Sterkano. Bogotá: Legis, 2007, p. 247. 
En México existe la figura del amparo constitucional, sin embargo, este únicamente se ha admitido contra la sentencia judicial dictada en el proceso de reconocimiento y ejecución de los laudos arbitrales, más no directamente contra el laudo ${ }^{29}$.

A consideración de CONEJERO RoOs la constitucionalización del arbitraje es "altamente desaconsejable" 30 pues eso está llevando a que los países latinoamericanos busquen mecanismos procesales constitucionales para asegurar los derechos fundamentales, y con ello, desconociendo los mecanismos legales que de forma efectiva resguardan la constitución. Es decir, la Constitución se convierte en norma de aplicación directa y devalúa la Ley que ha sido promulgada de conformidad con la misma Constitución. Lo anterior nos lleva a la pregunta de si la Ley de Arbitraje aún surte los efectos específicos que dotan de ventajas al proceso arbitral, cuando tales efectos pueden anularse por vía constitucional.

En relación a lo anterior cabe considerar el fallo de enero 17 de 2005 en el cual el Tribunal Supremo Español determinó:

"El Arbitraje es un medio heterónimo de arreglo de controversins que se fundamenta en la autonomía de voluntad de los sujetos privados, lo que constitucionalmente lo vincula con la libertad como valor superior del ordenamiento; y aquello que por, por voluntad expresn de las partes, se defiere al ámbito del proceso arbitral, por esa misma voluntad expresa de las partes queda sustraido al conocimiento del Tribunal Constitucional a través de un recurso de amparo en el que se invoquen las garantias del art. $24 \mathrm{CE}$, culyas exigencins se dirigen en principio a la actividad jurisdiccional del Estado, y que, con respecto al arbitraje solo proyecta sus garantías con el carácter de derechos fundamentales a aquellas fases del procedimiento arbitral y a aquellas actuaciones para las cuales la ley prevé la intervención jurisdiccional de los órganos judiciales del Estado (...) el recurso o acción de anulación y la ejecución forzosa del laudo"31.

29. Conejero Roos, Cristián. El Arbitraje Comercial Internacional en Iberoamérica: Un Panorama General. Madrid: La Ley, 2009, p. 95.

30. Ibidem.

31. Sentencia del Tribunal Supremo español 9/2005, de 17 de enero de 2005. 
En consecuencia, la tutela constitucional directa (en el arbitraje) solamente debería accionarse cuando los mecanismos legales de tutela previstos en la lex arbitri no son suficientes para resguardar los principios constitucionales.

En el caso del arbitraje internacional existen varios mecanismos para salvaguardar las conductas contrarias a las normas constitucionales, por ejemplo:

(i) En los países que utilizaron la Ley Modelo de UNCITRAL para expedir su Ley de Arbitraje, se prevé la acción de nulidad por violación de debido proceso (que ratifica las causales previstas en la Convención de Nueva York),

(ii) En los casos de falta de independencia de los árbitros, se prevén normas para la recusación de árbitros que evaden los conflictos de competencia sujetos a las normas del procedimiento civil.

(iii) En los procesos que tienen como parte a entes Estatales, legislaciones como la ecuatoriana requieren la autorización del Procurador General del Estado para suscribir el convenio arbitral.

\section{Consideraciones Finales}

El profesor Fernando Cantuarias considera que el "ámbito de revisión judicial de un laudo arbitral necesariamente condicionará la utilidad del arbitraje" 32 , es decir, si la ley dispone una revisión amplia que comprenda el fondo de la controversia, entonces el arbitraje es una suerte de primera instancia judicial. En cambio, si la ley no prevé ningún tipo de revisión judicial, se podría infe-

32. Cantuarlas Salanverky, Fernando. Arbitraje Comerial y de las liversiones. Lima: UPC, 2007, p. 373. 
rir que el arbitraje es un mecanismo potencialmente abusivo y peligroso.

Consecuentemente, la acción de nulidad como mecanismo de revisión judicial de los laudos constituye el punto medio entre las dos teorías, por un lado pretende evitar el exceso de poder de los árbitros, y por otro; evita la revisión del fondo de la controversia por parte de las cortes. Además, la acción de nulidad es el mecanismo previsto en la Ley para controlar y regular el debido proceso, sin que sea necesaria la revisión mediante acciones constitucionales como el amparo, en ciertos países, o acciones de protección para el caso ecuatoriano.

Sin perjuicio de que la mayoría de las leyes de arbitraje iberoamericanas reconocen el principio de inapelabilidad de los laudos de conformidad con el artículo 5 de la Ley Modelo de UNCITRAL, y que en consecuencia la intervención judicial en el arbitraje debe limitarse exclusivamente a los casos de auxilio judicial previsto en la ley de la materia (acción de nulidad y ejecución forzosa), la práctica demuestra que las cortes han extendido su injerencia en el arbitraje, sea por la aplicación de precedentes constitucionales o por la interpretación extensiva de las causales de nulidad.

La intrusión jurisdiccional, fuera de la prevista en la Ley (que debe ser el contrapeso al poder de los árbitros) desnaturaliza al proceso arbitral y menoscaba la garantía constitucional de libertad y autonomía negocial que fundamenta al arbitraje y alienta a los particulares a extraer su controversia de la jurisdicción ordinaria, además elimina las cualidades de celeridad y eficacia que caracterizan al arbitraje, convirtiéndolo en una primera instancia de un engorroso proceso judicial.

Asimismo, en Latinoamérica se evidencia una tendencia a constitucionalizar el arbitraje, asimilando el concepto de árbitro con el concepto de juez. Lo que permite que los laudos arbitrales sean impugnados en sede constitucional de la misma manera 
que las sentencias judiciales, desconociendo el efecto de res iudicatn del laudo y generando desconfianza e incertidumbre para quienes someten sus controversias a procesos arbitrales.

Para concluir concuerdo con DI Rosa ${ }^{33}$, quien considera que muchas de las lagunas de la cultura arbitral latinoamericana son atribuibles a la inercia del poder judicial en su adaptación a las nuevas corrientes. Consecuentemente, la cultura judicial latinoamericana enfrente el reto de cambiar la idea de competencia entre juez y árbitro por la idea de complementariedad entre el sistema arbitral y judicial.

33. Dr Rosa, Paolo y Rafael Cox Alomar. "Control Judicial del Arbitraje: Siempre Tributario de un Foro Local". En la Obra Colectiva: El Arbitraje Internacional: Tensiones Actuales, coordinada por Fernando Mantilla. Bogotá: Legis, 2007, p.251.

242 Revista Ecuntoriana de Arbitraje 